\title{
PONTES PROTENDIDAS DE MADEIRA: ALTERNATIVA TÉCNICO-ECONÔMICA PARA VIAS RURAIS ${ }^{1}$
}

\section{THALITA F. DA FONTE ${ }^{2}$, CARLITO CALIL JÚNIOR ${ }^{3}$}

\begin{abstract}
RESUMO: A necessidade de pontes novas e recuperação das existentes no Brasil é evidente, desde o âmbito municipal, estadual e até federal. A construção de malha rodoviária eficiente pode proporcionar, além do conforto aos usuários, diminuição do custo com o transporte de alimentos e outros produtos, visto que praticamente todo o transporte no País é feito por meio das rodovias. De acordo com estimativa feita pelo Laboratório de Madeiras e de Estruturas de Madeiras (LaMEM) do Departamento de Engenharia de Estruturas da Escola de Engenharia de São Carlos da Universidade de São Paulo, a necessidade de pontes de pequenos e médios vãos ultrapassa 100 mil unidades. Portanto, torna-se de extrema importância o estudo de novas tecnologias que sejam competitivas técnica e economicamente, de forma a minimizar os gastos com essas benfeitorias. Este trabalho diz respeito à viabilidade técnica e econômica para a construção de pontes de madeira laminada protendida transversalmente, para rodovias rurais ou secundárias. Esta análise foi realizada por meio do projeto, da construção e do monitoramento da primeira ponte protendida de madeira da América do Sul. Os resultados encontrados apontam baixo custo de material e de execução, facilidade e rapidez de execução, bem como elevado desempenho em campo.
\end{abstract}

PALAVRAS-CHAVE: pontes em placa, estruturas de madeira, protensão transversal.

\section{PRE-STRESSED TIMBER BRIDGES: ECONOMIC CHOICE FOR RURAL ROADS}

ABSTRACT: The demand of new bridges and rehabilitation of the existing ones in Brazil is evident, in the municipal, state and federal scope. The construction of efficient roads can provide, besides comfort to the users, a cost decrease for the transportation of food and other products, since almost all the transportation in the country is made through highways. According to the estimate made by the Wood and Timber Structures Laboratory (LaMEM) of São Paulo University, more than 100,000 of short and medium span bridges are necessary to improve Brazilian roads. Therefore, the study of competitive technologies is of extreme importance, in order to minimize the budget needed to these improvements. This work reports on a technical and economical viability analysis of transversally pre-stressed timber bridges, for the use in rural and secondary roads. The analysis was made through design, construction and monitoring of the first pre-stress-laminated timber bridge in South America. The results show high performance, low cost, easy and quick execution.

KEYWORDS: bridges in decks, timber structures, transversal stressing.

\section{INTRODUÇÃO}

A utilização de tabuleiros de madeira laminada protendida em pontes tem-se mostrado ótima alternativa para rodovias rurais ou secundárias. A madeira, ao contrário da crença popular, é ótimo material estrutural, desde que seja utilizada racionalmente. Se forem tratadas com material preservativo, como, por exemplo, CCA (Cobre, Cromo, Arsênio) ou CCB (Cobre, Cromo, Boro), as peças de madeira apresentam resistência aos organismos deterioradores e ao fogo. Dessa forma, é possível a construção de grandes estruturas, que devem manter sua integridade por longo período, como é o caso de pontes. O que acontece normalmente, é que a maioria das pontes de madeira

\footnotetext{
${ }^{1}$ Resumo apresentado no XXXIII Congresso Brasileiro de Engenharia Agrícola, 2 a 6 de agosto de 2004, São Pedro - SP.

${ }^{2}$ Eng ${ }^{a}$ Civil, Aluna de Doutorado, Laboratório de Madeiras e de Estruturas de Madeira, Departamento de Engenharia de Estruturas, Escola de Engenharia de São Carlos, USP, São Carlos - SP, Fone: (0XX16) 3373.9369, thalitaf@ sc.usp.br

${ }^{3}$ Eng ${ }^{\mathrm{o}}$ Civil, Professor Titular, Departamento de Engenharia de Estruturas, EESC-USP, São Carlos - SP.

Recebido pelo Conselho Editorial em: 29-9-2005
}

Aprovado pelo Conselho Editorial em: 2-5-2007 
existentes não foram projetadas e construídas por profissionais especializados, o que resultou em obras caras, sem segurança e de baixa durabilidade, que necessitam de reforço estrutural e geram visão negativa do emprego da madeira na construção civil.

As pontes laminadas protendidas transversalmente têm sido estudadas em várias partes do mundo e já somam mais de 2.500 unidades construídas, em vários países, como Estados Unidos, Austrália, Canadá, Japão, Alemanha e outros, sempre mostrando elevado desempenho e durabilidade, facilidade e rapidez de execução, a baixo custo (PRATA, 1995). A aplicação de protensão transversal em tabuleiros laminados de madeira, por meio da inserção de barras de aço de alta resistência em furos executados nas lâminas, perpendicularmente às fibras da madeira, comprimindo-as, confere ao tabuleiro um comportamento de placa, mobilizando-o integralmente com o carregamento dos veículos, e não somente uma área próxima ao carregamento. Dessa forma, o sistema apresenta baixo consumo de madeira (cerca de $0,30 \mathrm{~m}^{3}$ por metro quadrado de ponte construída), diminuindo o custo da superestrutura e das fundações (FONTE, 2004).

Este trabalho apresenta os conceitos básicos do sistema construtivo e análise de desempenho e de custo, por meio da construção e do monitoramento de um protótipo em escala real na cidade de São Carlos - SP, sendo a primeira ponte da América Latina que utiliza o sistema. Na Figura 1, é mostrado o desenho esquemático da estrutura do sistema.

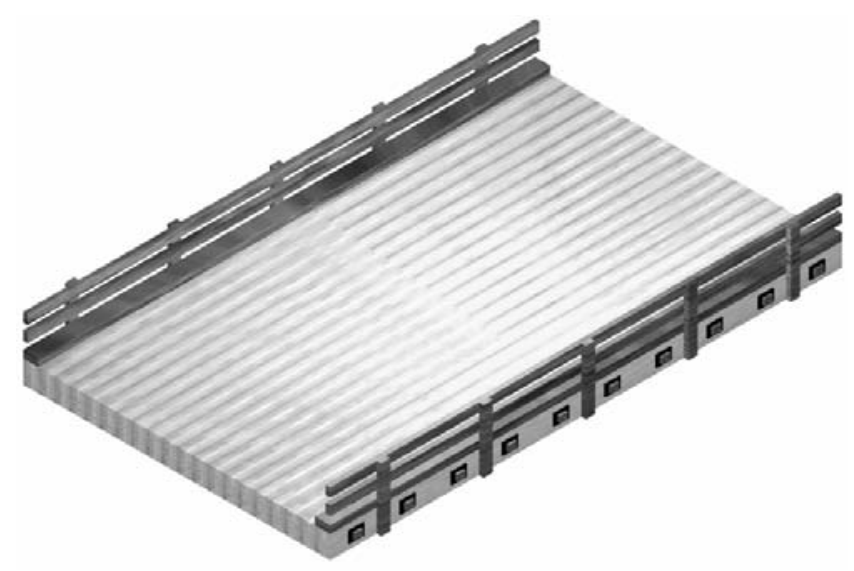

FIGURA 1. Desenho esquemático de ponte de madeira laminada protendida.

A estrutura básica das pontes em madeira laminada protendida consiste de uma placa de madeira laminada protendida, apoiada ao longo das extremidades longitudinais, na fundação. Entre esses elementos, é necessário um aparelho de apoio, como, por exemplo, de neoprene. Os tabuleiros são construídos com madeira tratada contra agentes biodeterioradores, com espessuras de 5 a $10 \mathrm{~cm}$ e altura, em função do projeto, de 13 a $40 \mathrm{~cm}$. Os tabuleiros podem ser construídos com qualquer espécie de madeira, desde que cumpram requisitos de resistência e rigidez de projeto. O sistema é ideal para pequenos vãos (até $12 \mathrm{~m}$ ), devido à máxima altura da lâmina, que é possível encontrar comercialmente, a menos quando associado a seções transversais compostas (FONTE, 2004). Na Figura 2, são mostradas as associações mais usuais. Quando o vão a ser vencido superar o limite de comprimento das peças de madeira, pode-se recorrer à utilização de juntas de topo (Figura 3), que são juntas serradas, mas não aparelhadas, sem grandes prejuízos de resistência e de rigidez.

As barras de protensão (metálicas) devem ter diâmetro entre 16 e $35 \mathrm{~mm}$, e resistência mecânica entre 827 e $1.033 \mathrm{MPa}$. Todos os elementos metálicos devem ser protegidos contra a corrosão. Na Figura 4, é mostrado como é realizada a inserção da protensão no tabuleiro. As pontes protendidas podem ser montadas no local da instalação ou em outro local, com maior controle de qualidade. 


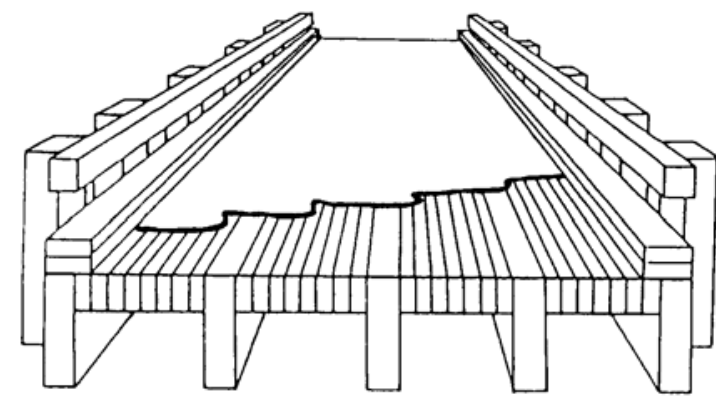

seção T

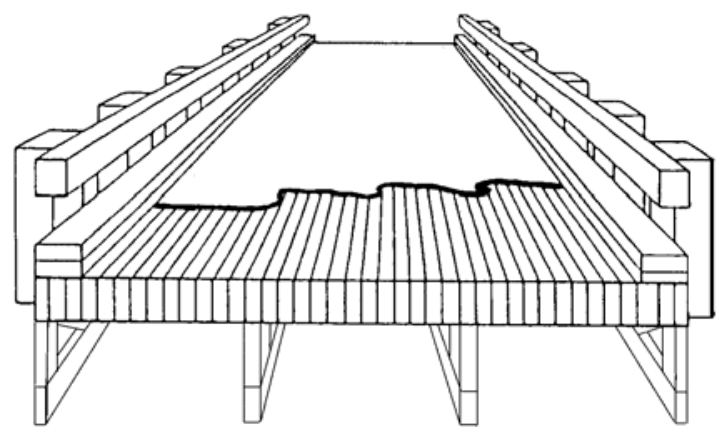

seção T com vigas treliçadas

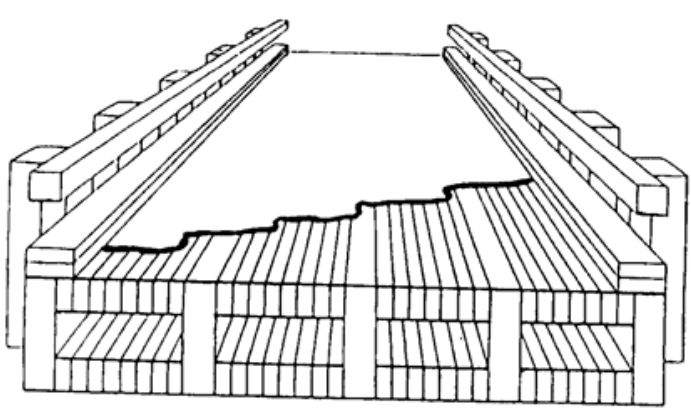

seção celular

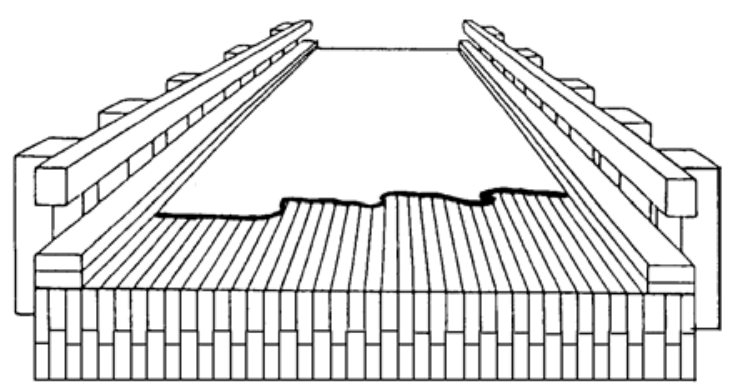

seção mista

FIGURA 2. Seções transversais mais usuais.

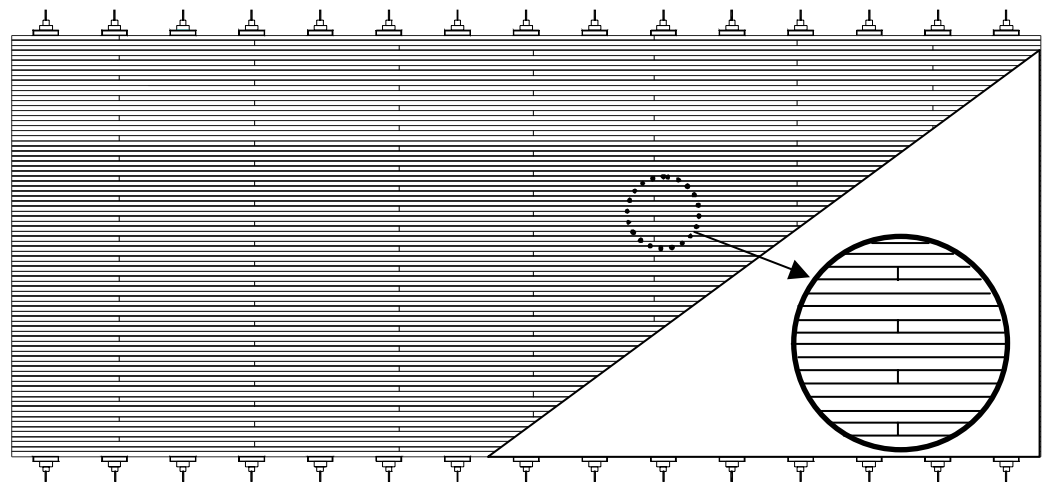

FIGURA 3. Juntas de topo, a cada quatro vigas.

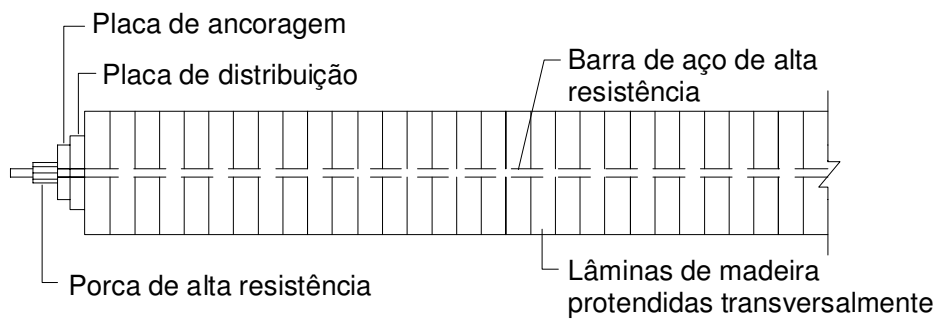

FIGURA 4. Aplicação de protensão transversal. 
Para que a placa se comporte da maneira desejada, foi necessário que as barras de aço fossem tensionadas com o auxílio de um cilindro hidráulico, até o valor estipulado em projeto, comprimindo as vigas de madeira. Quando isso ocorreu, o atrito existente entre duas lâminas de madeira fez com que elas respondessem solidariamente a qualquer ação externa. Dessa forma, o tabuleiro passou a se comportar como uma placa única de madeira, o que gera economia de material necessário.

\section{MATERIAL E MÉTODOS}

Este trabalho é resultado do projeto e construção de uma ponte protendida de madeira, em São Carlos - SP. Todos os processos envolvidos, bem como o custo e o tempo de execução de cada etapa, foram analisados, sendo as características do tabuleiro mostradas na Tabela 1.

TABELA 1. Características do tabuleiro.

\begin{tabular}{ccccccc}
\hline Vão & $\begin{array}{c}\mathrm{N}^{\mathrm{o}} \text { de Faixas } \\
\text { de tráfego }\end{array}$ & Largura & Altura & Juntas de Topo & Pavimento & Madeira \\
\hline $800 \mathrm{~cm}$ & 1 & $400 \mathrm{~cm}$ & $25 \mathrm{~cm}$ (projetada) & $\begin{array}{c}\text { A cada quatro } \\
\text { vigas }\end{array}$ & $\begin{array}{c}5 \mathrm{~cm} \text { de concreto } \\
\text { asfáltico }\end{array}$ & $\begin{array}{c}\text { Eucalipto citriodora } \\
\text { tratado com CCA }\end{array}$ \\
\hline
\end{tabular}

O trem-tipo adotado (veículo de projeto) foi o máximo permitido pelas normas brasileiras para o uso de rodovias, que equivale a um caminhão com três eixos, pesando 15 toneladas cada, comumente utilizado para escoamento agrícola (Figura 5). Na Figura 6, é mostrada a sequiência de construção, que foi composta por:

- Pré-montagem: o tabuleiro foi montado, inserindo-se cada lâmina de madeira em um gabarito executado com as barras de protensão e algumas lâminas (Figura 6a);

- Protensão do tabuleiro: as barras metálicas foram tensionadas, tomando-se o cuidado de respeitar os limites de escoamento das barras, com segurança. Se o tabuleiro for montado em laboratório, pode ser aplicada somente uma pré-protensão, bastante inferior à necessária (Figura $6 b)$;

- Içamento e transporte: esta etapa é necessária quando o tabuleiro não for montado diretamente no local e deve ser feita com bastante cuidado, sem movimentos bruscos Figuras (6c e $6 \mathrm{~d})$

- Instalação: o tabuleiro deve ser posicionado no local, e a protensão deve ser reaplicada;

- Reprotensões: dependendo da espécie de madeira, são necessárias reprotensões no tabuleiro. Recomenda-se revisão das forças e reaplicação, se necessário, aos 2; 7 e 60 dias.

O custo de materiais foi comparado ao custo médio de pontes de concreto para vão similar, obtido por meio de informação do Departamento de Estradas de Rodagem do Estado de São Paulo, de acordo com FONTE (2004).

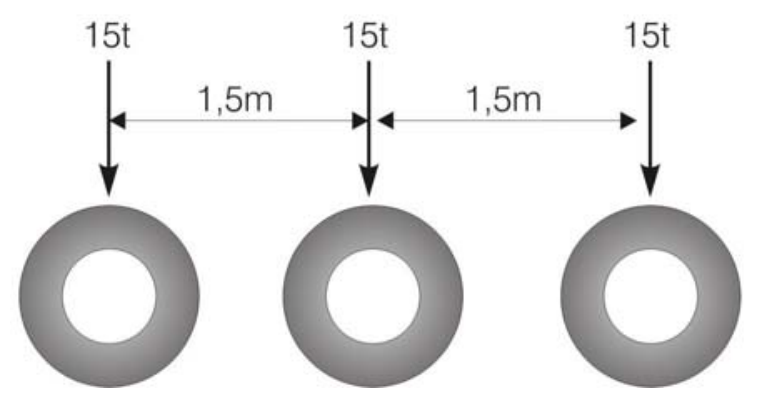

FIGURA 5. Trem-tipo adotado (ABNT,1984). 


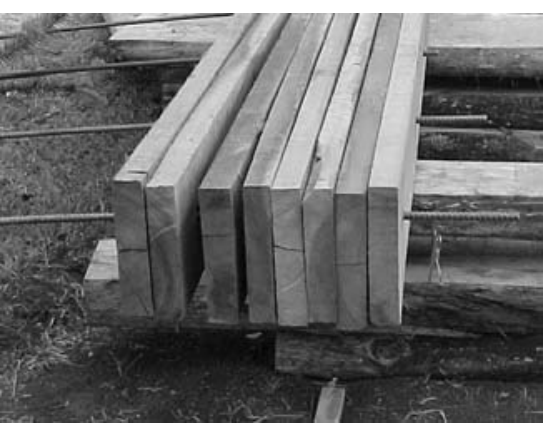

(a) pré-montagem

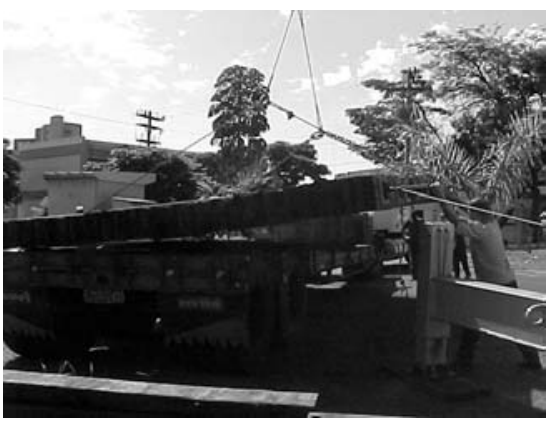

(d) transporte

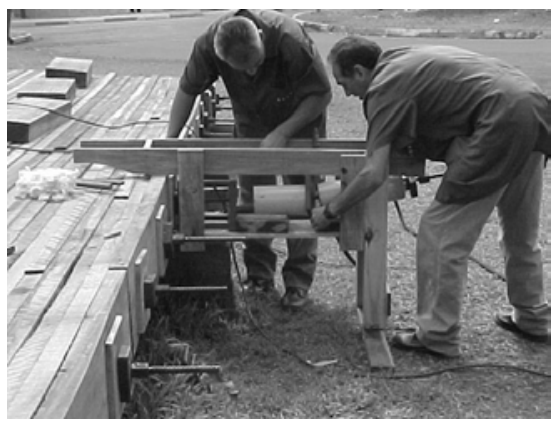

(b) protensão

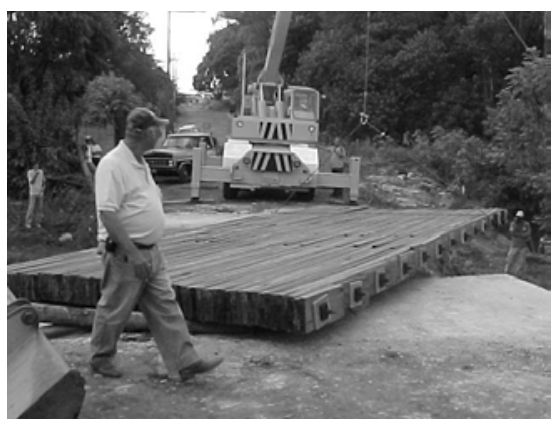

(e) instalação

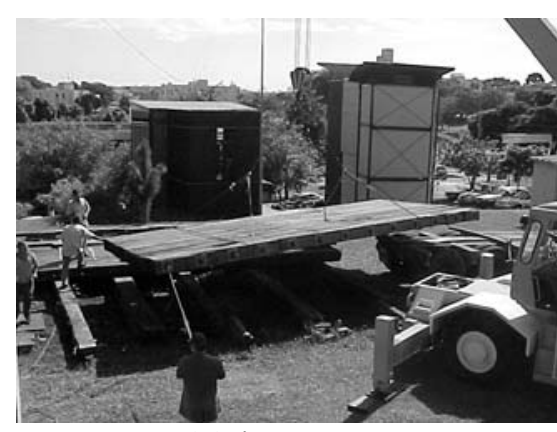

(c) içamento

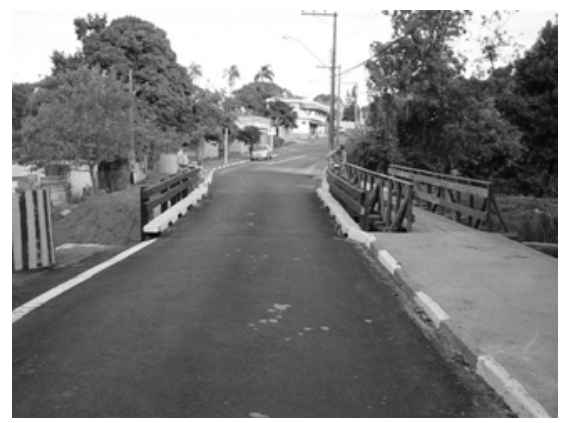

(f) vista final

FIGURA 6. Seqüência de construção.

O desempenho do tabuleiro foi medido na construção e seis meses após, por meio de provas de carga, que consistem em medir os deslocamentos obtidos no centro do vão para a ponte carregada com um caminhão de configuração próxima ao idealizado em projeto. Para executar o procedimento, foram pendurados metros de carpinteiro na face inferior do tabuleiro e, com o auxílio de um nível óptico, medido o deslocamento vertical (Figura 7). Como se trata de uma ponte de pequeno vão, somente os eixos traseiros solicitariam o tabuleiro. Os valores foram comparados com os valores previstos numericamente por meio do software "Orthotropic Timber Bridges" OTB (LINDQUIST et al., 2004), desenvolvido no Laboratório de Madeiras e de Estruturas de Madeira (LaMEM), especificamente para o caso de pontes de madeira em placa. Utilizou-se do peso real dos caminhões, por eixo, e os resultados também foram comparados aos valores máximos permitidos pela norma brasileira NBR 7190 (ABNT,1997). Em campo, foi medido o vão real da ponte, para o ajuste dos dados. O caminhão foi posicionado na porção central e da extremidade transversal do tabuleiro. As posições reais dos apoios foram avaliadas, o que forneceu vão de 5,96 $\mathrm{m}$, ao invés dos $8,00 \mathrm{~m}$ de projeto. Esse dado foi utilizado nas análises de desempenho.

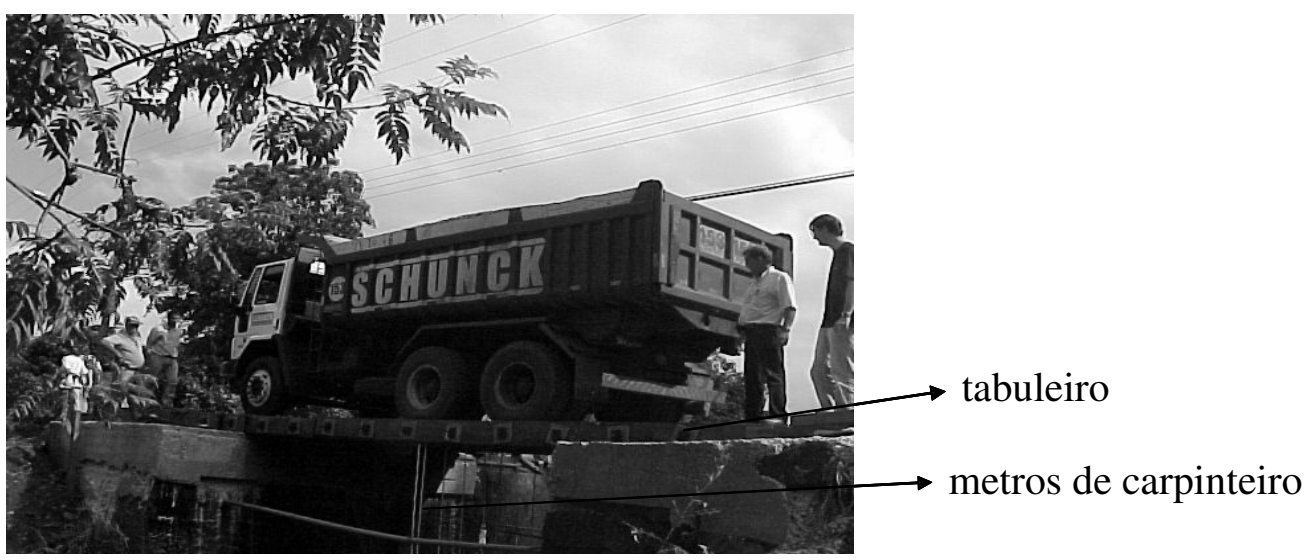

FIGURA 7. Prova de carga. 


\section{RESULTADOS E DISCUSSÃO}

Não foram encontradas grandes dificuldades para a construção da ponte protendida de madeira. Todos os processos requereram pouca mão-de-obra, tanto comum quanto especializada. A montagem, em laboratório, contou com quatro trabalhadores e teve duração de cinco dias, em jornada de $8 \mathrm{~h}$ de trabalho. A protensão durou dois dias, com dois técnicos de laboratório. $\mathrm{O}$ transporte e a instalação duraram duas semanas, trabalhando-se cinco dias por semana, com cinco operários. Na Tabela 2, são mostrados o custo dos materiais estruturais utilizados e o custo estimado para uma ponte de concreto, do mesmo vão, em que se percebe que a ponte protendida transversalmente de madeira apresentou custo bem menor que o comum.

TABELA 2. Custo da ponte protendida de madeira.

\begin{tabular}{lc}
\hline Material & Custo $(\mathrm{R} \$)$ \\
\hline Madeira & $8.870,00$ \\
Sistema de protensão (completo) & $1.500,00$ \\
Demais elementos metálicos & 800,00 \\
Custo de materiais da ponte protendida & $11.170,00\left(186,17 \mathrm{~m}^{-2}\right)$ \\
Custo de materiais estimado para pontes de concreto & $32.000,00\left(1.000,00 \mathrm{~m}^{-2}\right)$ \\
\hline Fonte: FONTE (2004)
\end{tabular}

Nas Figuras 8 e 9, são mostrados os resultados obtidos nas provas-de-carga, comparado-os aos esperados numericamente. As escalas máximas das figuras foram ajustadas aos valores máximos permitidos por normas. Na Tabela 3, são mostrados os principais resultados de desempenho obtidos no tabuleiro, no momento da construção e seis meses após, para o carregamento posicionado centralmente na direção transversal e longitudinalmente, de forma a obter a máxima solicitação. Pelos resultados, pode-se perceber que os deslocamentos obtidos foram próximos aos previstos numericamente e inferiores aos máximos permitidos pelos códigos normativos vigentes, o que valida as metodologias de cálculo e de execução empregadas.
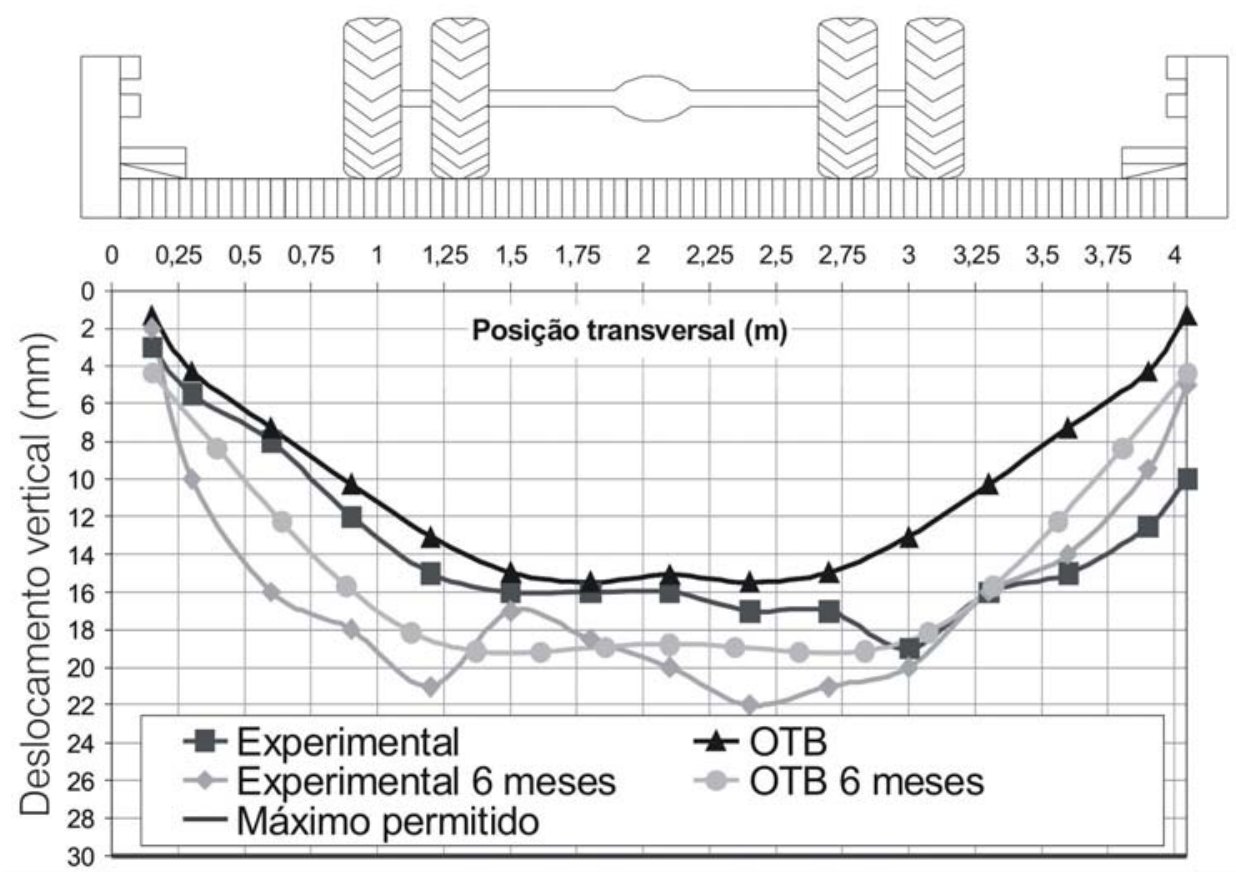

FIGURA 8. Desempenho no centro do vão da ponte, comparado aos resultados esperados, para o carregamento centrado transversalmente. 


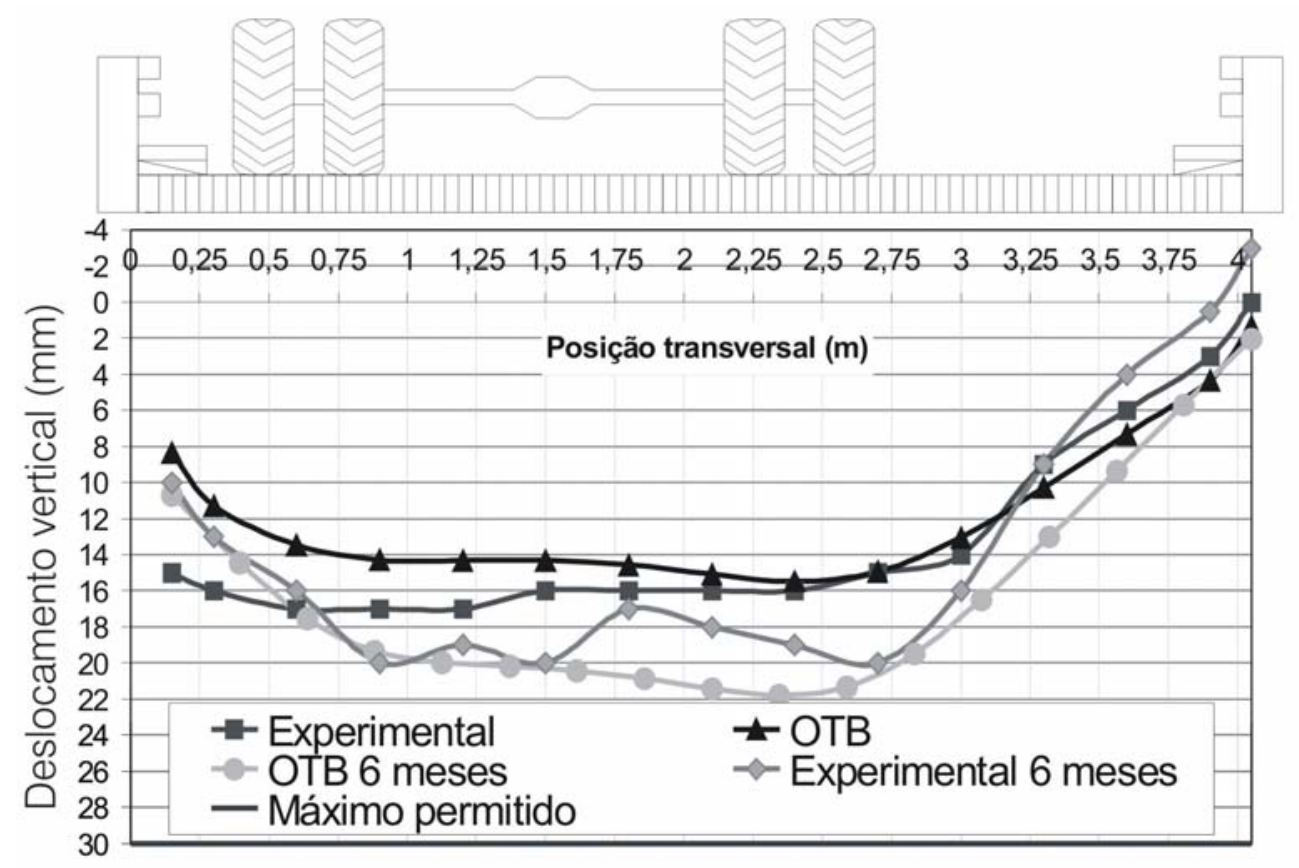

FIGURA 9. Desempenho no centro do vão da ponte, comparado aos resultados esperados, para o carregamento excêntrico axialmente.

TABELA 3. Dados das provas de carga executadas.

\begin{tabular}{cccc}
\hline Prova de carga & $\begin{array}{c}\text { Deslocamento máximo } \\
\text { obtido no centro do } \\
\text { vão }(\mathrm{cm})\end{array}$ & $\begin{array}{c}\text { Deslocamento máximo } \\
\text { previsto no centro do vão - } \\
\text { OTB }(\mathrm{cm})\end{array}$ & $\begin{array}{c}\text { Deslocamento máximo } \\
\text { permitido - NBR } \\
7190: 1997(\mathrm{~cm})\end{array}$ \\
\hline Construção & 1,9 & 1,5 & 3,0 \\
6 meses & 2,1 & 1,9 & 3,0 \\
\hline
\end{tabular}

\section{CONCLUSÕES}

A ponte de madeira laminada protendida transversalmente apresentou excelente desempenho para as condições climáticas e de material. Os resultados obtidos por meio das provas de carga foram próximos aos previstos e menores que o máximo permitido por norma. $\mathrm{O}$ custo de materiais encontrados foi cerca de um quinto do custo estimado para pontes de concreto, necessitando de pouca mão-de-obra especializada e tempo de execução. Dessa forma, verificaram-se facilidade e rapidez de execução, além de custo de materiais e tecnológico bastante competitivo com outros sistemas comumente utilizados em vias rurais.

\section{AGRADECIMENTOS}

Ao CNPq e à FAPESP, pelo apoio financeiro concedido a esta pesquisa.

\section{REFERÊNCIAS}

ABNT. ASSOCIAÇÃO BRASILEIRA DE NORMAS TÉCNICAS. NBR 7188/1984. Carga móvel em ponte rodoviária e passarela de pedestre: procedimento. Rio de Janeiro, 1984.

ABNT. ASSOCIAÇÃO BRASILEIRA DE NORMAS TÉCNICAS. NBR 7190/97. Projeto de estruturas em madeira: procedimento. Rio de Janeiro, 1997.

FONTE, T.F. Pontes protendidas de Eucalipto citriodora. 2004. 267 f. Dissertação (Mestrado em Engenharia de Estruturas) - Escola de Engenharia de São Carlos, Universidade de São Paulo, São Carlos, 2004. 
LINDQUIST, M.; GÓES, J; CALIL JUNIOR, C.; DIAS, A.A. A software for analyzing orthotropic bridge. Maderas-Ciencia y Tecnologia, Universidad Del Bío-Bío, Chile, v.6, n.1, p.241-5, maio/ago. 2003.

PRATA, D.G. Pontes protendidas de madeira. 1995. 312 f. Tese (Doutorado em Engenharia Civil) - Escola de Engenharia de São Carlos, Universidade de São Paulo, São Carlos, 1995. 